biological validity. So, if the hypothesis is that social adversity or racial life events might be aetiologically important, as in my $B M J$ paper $(B M J, 311,1325-1328)$ then it is consistent to look at "Afro-Caribbeans" as a homogeneous group. I would certainly not limit the problem to the term Afro-Caribbeans. The situation is dynamic and a minefield. Researchers have to maintain scientific accuracy, house style of a journal, readability, the need for access to their paper through electronic searches, the fact that there are pre-existing terms that may take some time to change and the fact that terminology is often thought of as a political statement. They also have to understand the limitations of their data set and try to use groupings which are consistent with the hypothesis which is being tested.

There is ongoing work to produce a template for terminology for ethnic groups for research. The aim is to produce clear and understandable guidelines for researchers. The best advice is to be as accurate as possible and to clearly state in the methods how the groups were demarcated and how this logically flowed from the hypothesis under consideration. If science provides better ways of looking at differences between peoples, then a paper which accurately describes what has been done, regardless of the terminology used, may be properly put into context.

K. J. MCKENZIE, 18, Square Marie Louise, BTE 34, Brussels 1000

\section{Community Drug Problem Service}

Sir: Like many others, I have tried and failed to obtain close cooperation from primary care colleagues in the treatment of patients with drug problems. The achievements of Edinburgh's Community Drug Problem Service in this direction are clear from Dr Greenwood's paper (Psychiatric Bulletin, 20, 8-1 1) but I would welcome clarification of some of the data presented.

Although the proportion of new referrals injecting fell between 1988 and 1993, the actual numbers of injectors seen rose from 83 to 127 . Similarly the number of those admitting sharing remained virtually constant, 76 and 74 . Regarding this latter figure I sometimes suspect that over the 5 years described, drug users learnt that they should not share and now deny sharing to avoid any embarrassment. In considering the HIV rates it would be interesting to know how many individuals of which groups were tested. If all those attending as new clients were tested then 18 were positive in 1988 compared with 42 in 1993. If only those with a history of injecting were tested these figures become 17 and 18 respectively.
Presenting data on the proportion of those new patients attending who had never been seen before, and the ages of new referrals between 1988 and 1993, might add further weight to Dr Greenwood's cautious optimism that there are real changes in injecting behaviour in Edinburgh, and not merely changes in those who attend services.

\section{A. J. MCBRIDE, Lwyn-yr-Eos Clinic, Main Road,} Church Village, Pontypridd CF38 1RN

Sir: Dr McBride is correct in questioning the statistical significance of an apparent fall in the proportion of drug users injecting at the time of referral to our drug service. This need not necessarily reflect a change in injecting behaviour among the drug using population at large but rather the recruitment of more non-injectors into the service.

However, from the whole sample (and here I must correct my original text), in $1988,97 \%$ had ever injected and $88 \%$ had injected in the past month, whereas in $1993,43 \%$ had ever injected but only $14 \%$ of the whole sample in the past month. This suggests that ever injectors were less likely to be regular injectors in 1993.

Independent studies (Haw, 1993), Scottish Drug Database (NHS in Scotland, 1992) and HIV Sero-prevalence (Davies et al, 1995) research also confirm a trend away from injecting drug use in Lothian in independently recruited samples.

I do not believe that under reporting due to embarrassment accounted for the fall in reported rates of equipment sharing. Nevertheless Griffin et al have already pointed out the persistence of equipment sharing among a small but consistent cohort of injecting drug users.

The HIV rate of those tested prior to referral was neither for all new clients nor all injectors. In 1988 , of 81 people tested 15 were positive $(21 \%)$. In 1993, of 137 tested 11 were positive (8\%). Most of those tested in each year were past injectors. There was no service requirement for a test to be taken.

In 1988, all patients were new to the service but by $199321 \%$ of referrals had been seen previously but not in the past six months. Ages of new referrals changed from a mean of 26 and median of 25 in 1988 to a mean of 25 and a median of 24 by 1993 (when the number of teenagers recruited to the service had increased from $9 \%$ to $23 \%$ ).

Haw, S. (1993) Pharmaceutical Drugs and Ilicit Drug Use in Lothian Region. Edinburgh: Centre for HIV/AIDS and Drug Studies.

National Health Service in Scotland (1992) Scottish Drug Misuse Database Bulletin. Information and Statistics Dtvision. National Health Service in Scotland. Edinburgh. 
Davies, A. G., DOMINY, N. J., Peters, A. D., et al (1995) HIV in injecting drug users in Edinburgh: prevalence and correlates. Journal of AIDS and Human Retrovirology. 8, 399-405.

GRIFFIN, S., PETERS, A. \& REID, M. (1993) Drug misusers in Lothian. Changes in injecting habits 1988-90. British Medical Journal, s06, 693.

J. GreenwoOd, Community Drug Problem Service, Royal Edinburgh Hospital, 40 Colinton Road, Edinburgh EH10 5BT

\section{Service contact prior to suicide}

Sir: We were interested to read Meats \& Solomka's perspective on suicide in Central Nottinghamshire from 1987-1991 (Psychiatric Bulletin, 19, 666-669) and their points regarding consulting behaviour and potential for intervention.

We conducted a survey of Nottingham suicides during 1994. Data were collected from Coroner's records, hospital database and a postal questionnaire $(75 \%$ returned) from general practitioners (GP) who encountered suicides, or open and misadventure verdicts judged as suicides. Fifty-seven deaths by suicide were identified (7.8 per 100000 pop.), $75 \%$ male, and $54 \%$ men under 35 years.

We wish to make two points. Firstly, a considerable number of Meats \& Solomka's "nonconsulters" (i.e. no primary or secondary service contact in 12 months prior to death) may have attended casualty or non-psychiatric medical services within this time. In our sample $37 \%$ of cases had attended casualty (often with deliberate self-harm), and $32 \%$ other medical services, and for seven cases casualty was their only contact. These casualty attenders in particular represent a significant group since they are at known risk of death within one year of DSH and suggest potential for targetable intervention in a readily identifiable group. This compares with identification of potential suicides within primary care, a comparattvely rare event estimated as one in 51199 GP consultations (MacDonald, 1992).

Secondly, although GP consultations by potential suicide cases increased before death and provided an "opportunity to be recognised", in our study the issue of suicide was not raised with over half of cases despite recognition of psychological distress in $67 \%$ cases and prior DSH in $29 \%$. Indeed, only one of 43 GPs thought their particular suicide cases preventable, suggesting an overall reluctance by GPs to see suicide prevention as practically relevant to them.

MACDONALD, A. (1992) Suictde prevention by GPs? British Journal of Psychiatry, 161, 574.

J. Milton AND B. Ferguson, East \& Carlton Mental Health Team, Stonebridge Centre, Carlton Road, Nottingham NG3 2FH

\section{Distinction awards}

Sir: Dr Hyde (Psychiatric Bulletin, 20, 117) reports that consultants who change posts may be inadequately considered for $\mathrm{C}$ distinction awards (now 'discretionary points') because their achievements in a previous position are not known.

There is another hazard that also applies to higher awards. Distinction awards are based on merit not seniority but award committees are favourably influenced by the duration of consultant responsibility. In the case of consultants who change posts their date of achieving consultant status is sometimes recorded for award committees as the date of last appointment. The error of course shortens by some years the true period of consultantship.

Consultants who change jobs would be wise to ensure that their new Regional Health Authority and the Secretariat of the Advisory Committee on Distinction Awards register for this purpose the first date of consultant appointment.

J. S. MADDEN, 87 Mill Lane, Upton-by-Chester, Chester CH2 $1 \mathrm{BS}$

\section{The rise and fall of anti-psychiatry}

Sir: Nasser (Psychiatric Bulletin, 19, 743-746) makes some interesting points, several of which merit comment. Cooper defines "anti-psychiatry" quite specifically in Psychiatry and Anti-Psychiatry (1970), a text cited by Nasser. Cooper's aim appears to have been to coin a term which specifies a practice which is the converse of orthodox practice. His use of the term is clear:

"A more profound questioning has led some of us to propose conceptions and procedures that seem quite antithetic to the conventional ones - in fact what may be regarded as a germinal ant1psychiatry."

Commentators have often misunderstood the term as simply one more way of expressing antagonism to orthodox psychiatric practice rather than an antithesis. This mistaken use of the term loses the subtlety of the original, and is often misapplied to a heterogeneous collection of views, many of which would have found approval with Cooper or Laing.

Laing and anti-psychiatry are taken to be synonymous by some authors but he appears not to promote the term in his writings, to have neither made a contribution to, nor offered an endorsement of Laing and Anti-Psychiatry (1971) and in Wisdom, Madness and Folly (1985) wrote

"I have never called myself an anti-psychiatrist, and have disclaimed the term from when first my friend and colleague, David Cooper, introduced it". 